\title{
TAI CHI SEBAGAI MODALITAS REHABILITASI STROKE
}

\author{
TAI CHI AS A MODALITY FOR STROKE REHABILITATION
}

Jimmy, * Yudy Goysal, * Andi Kurnia Bintang, * Muhammad Iqbal Basri, * Nilla Mayasari**

\begin{abstract}
Tai Chi is a Chinese traditional mind-body exercise and is well known for its slow and graceful movements. Tai Chi has been practiced for centuries and has become a popular exercise worldwide in recent years. Tai Chi is beneficial to cardiorespiratory function, muscular strength, balance, flexibility, microcirculation, psychological profile and quality of life. Tai Chi can be prescribed as an alternative exercise programme for selected patients with cardiovascular, orthopaedic, or neurological diseases. Recent studies prove that Tai Chi is safe and effective for patients with neurological diseases (e.g., stroke, Parkinson's disease, traumatic brain injury, multiple sclerosis, cognitive dysfunction). Tai Chi appears to be beneficial for the rehabilitation of stroke, a leading cause of disability worldwide.
\end{abstract}

Keywords: Rehabilitation, stroke, Tai Chi

\section{ABSTRAK}

Tai Chi adalah suatu latihan pikiran-badan tradisional Tiongkok dan terkenal dengan gerakannya yang lambat dan anggun. Tai Chi telah dipraktikkan selama berabad-abad dan telah menjadi latihan populer di seluruh dunia dalam beberapa tahun terakhir. Tai Chi bermanfaat untuk fungsi kardiorespirasi, kekuatan otot, keseimbangan, kelenturan, mikrosirkulasi, psikologis dan kualitas hidup. Tai Chi dapat diberikan sebagai program latihan alternatif untuk pasien dengan penyakit kardiovaskular, ortopedis, dan neurologis. Penelitian terkini membuktikan bahwa Tai Chi adalah aman dan efektif untuk pasien dengan penyakit-penyakit neurologis (seperti stroke, penyakit Parkinson, cedera otak traumatik, multipel sklerosis, disfungsi kognitif). Tai Chi tampaknya bermanfaat untuk rehabilitasi stroke, suatu penyebab utama kecacatan di seluruh dunia.

Kata kunci: Rehabilitasi, stroke, Tai Chi

*Departemen Neurologi FK Universitas Hasanuddin/RSUP Dr. Wahidin Sudirohusodo, Makassar; **Departemen Kedokteran Fisik dan Rehabilitasi FK Universitas Hasanuddin/RSUP Dr. Wahidin Sudirohusodo, Makassar. Korespondensi: jimmy.jitacitto@gmail.com.

\section{PENDAHULUAN}

Tai Chi Chuan (Tai Chi) adalah suatu latihan pikiran-badan tradisional Tiongkok dan sekarang ini menjadi populer di seluruh dunia. Selama praktik Tai Chi, pernapasan diafragma dalam terintegrasi dalam pergerakan tubuh untuk mendapatkan keseimbangan harmoni antara badan dan pikiran dan untuk memfasilitasi aliran energi internal (Qi). Partisipan dapat memilih untuk melakukan postur Tai Chi yang lengkap atau postur tertentu sesuai dengan kebutuhan mereka. Tai Chi mempunyai keuntungan yang signifikan untuk promosi kesehatan. Dengan mempraktikkan Tai Chi secara reguler akan memperbaiki kapasitas aerobik, kekuatan otot, keseimbangan, kesehatan terkait kualitas hidup, dan kesejahteraan psikologis. ${ }^{1}$

Berbagai studi membuktikan bahwa Tai Chi aman dan efektif untuk pasien-pasien dengan penyakit neurologi (stroke, penyakit Parkinson, cedera kepala, multipel sklerosis, disfungsi kognitif), penyakit reumatologi (reumatoid artritis, spondilitis ankilosing, dan fibromialgia), penyakit jantung (infark miokard akut, pembedahan bypass arteri koroner, dan gagal jantung), penyakit paru obstruktif kronik, dan kanker payudara. Tai Chi merupakan latihan aerobik dengan intensitas ringan hingga sedang yang populer di seluruh dunia, dan penelitian terhadapnya sedang berkembang. ${ }^{1}$

Latihan Tai Chi juga berbiaya rendah karena tidak membutuhkan peralatan dan fasilitas. Di komunitas Tionghoa, kebanyakan instruktor adalah sukarelawan, sehingga partisipan hanya perlu membayar biaya latihan minimum. Di Amerika Serikat, biaya langsung program $T a i$ Chi adalah sekitar $\$ 3,5$ per orang per sesi, yang terjangkau untuk kebanyakan partisipan. Di Taiwan, latihan Tai Chi formal untuk partisipan pemula biasanya berkisar antara $\$ 20-40$ per bulan. ${ }^{1}$

\section{PEMBAHASAN}

Tai Chi Chuan merupakan salah satu cabang seni bela diri Tiongkok yaitu wushu dan telah berkembang sejak abad 17 di Tiongkok. Gerakan 
yang lambat, luwes, dan anggun dari Tai Chi berasal dari Taoisme. Taoisme sendiri merupakan filosofi Tiongkok dan telah diajarkan oleh Lao Tze pada abad ke 5-4 sebelum masehi. Doktrin Taoisme adalah fokus terhadap ketenangan pikiran dan tujuannya untuk mencapai umur panjang dengan meditasi dan modifikasi pola hidup. ${ }^{1}$

Dikenal sebagai Taijiquan atau Tai Chi Chuan di Tiongkok, Tai Chi kadang-kadang juga disebut sebagai tinju bayangan (shadow boxing). Kata Tai Chi artinya tidak terbatas dan mencerminkan konsep Tiongkok kuno bagaimana alam semesta berkembang. Berdasarkan filosofi Tiongkok kuno, alam semesta ini dimulai dari suatu kekosongan yang luas. Hal ini berkembang menjadi pernyataan Tai Chi yang berarti tidak terbatas. Kata quan atau chuan berarti "tinju". Hal ini diberikan pada akhir dari penamaan semua gaya seni bela diri Tiongkok, sebagai contoh xingyiquan dan shaolinquan. Tai Chi Chuan adalah suatu seni bela diri yang berdasarkan pada teori alam semesta. Dipercaya bahwa mempelajari alam semesta akan memberikan kita pemahaman tentang alam semesta kecil yaitu tubuh manusia. ${ }^{2}$

Dalam perjalanannya, Tai Chi dibedakan menjadi 5 gaya utama yaitu Chen, Yang, Hao, Wu, dan Sun yang dipraktikkan sampai sekarang. Kelima gaya tersebut mempunyai karakteristiknya masingmasing. Tai Chi adalah suatu sumber pengetahuan yang luas yang merupakan akumulasi dari hasil kerja banyak orang yang berdedikasi sepanjang abad. Setiap gaya mempunyai karakteristik yang berbeda dan unik dan berharga dengan caranya sendiri. ${ }^{1-2}$

\section{Karakteristik Dasar Tai Chi}

Gaya klasik Tai Chi merupakan bentuk-bentuk yang kompleks dan membutuhkan waktu lama untuk mempelajari dan mempraktikkannya. Oleh karena itu, banyak bentuk Tai Chi yang sederhana dikembangkan untuk memperpendek periode latihan. Variasi dalam pendekatan latihan menghasilkan perbedaan signifikan dalam intensitas dan efek latihan. Tai Chi dilakukan dalam posisi semisquat, dan intensitas latihan dapat dengan mudah disesuaikan dengan mengatur kecepatan dan tinggi postur. ${ }^{1}$

Karakteristik $\mathrm{Tai} C h i$ adalah konsentrasi pikiran dengan kontrol pernapasan, latihan seluruh badan dengan postur semisquat dan pergerakan badan terus menerus, melengkung, dan spiral. ${ }^{1}$

Tai Chi dapat dipraktikkan sendiri atau dalam latihan grup dan mempunyai keuntungan yang signifikan untuk fisik, emosi, dan fungsi sosial. Partisipan dapat mempraktikkan beberapa pergerakan Tai Chi untuk mencapai manfaat kesehatan tertentu seperti fleksibilitas dan keseimbangan, termasuk meningkatkan kapasitas aerobik atau kekuatan otot. ${ }^{1}$

\section{Intensitas Latihan}

Intensitas latihan Tai Chi tergantung pada gaya latihan, postur, dan durasi. Variasi dalam pendekatan latihan menghasilkan perbedaan besar dalam intensitas latihan. Dalam keadaan stabil dari praktik Tai Chi, denyut jantung rata-rata adalah 58\% dari cadangan denyut jantung (heart rate reservel HRR), dan pengambilan oksigen adalah 55\% dari pengambilan oksigen puncak $\left(\mathrm{VO}_{2 \text { peak }}\right)$. HRR adalah perbedaan antara denyut jantung maksimum dan denyutjantung istirahat. Angka ini biasanya digunakan untuk membentuk daerah latihan berdasarkan denyut jantung berdasarkan metode cadangan denyut jantung. Metode HRR didemonstrasikan sebagai berikut: Target $\mathrm{HR}=\left[\left(\mathrm{HR}_{\max }-\mathrm{HR}_{\text {res }}\right) x \%\right.$ intensity desired] $+\mathrm{HR}_{\text {rest }}$. Oleh karena itu, gaya Tai Chi yang sesuai dan pergerakan pilihan dapat dipilih dan disesuaikan dengan kebutuhan partisipan. ${ }^{1}$

\section{Aspek Biomekanikal}

Tai Chi gait (TCG) mempunyai postur yang rendah sehingga terdapat suatu distribusi berat badan yang merata antara kaki depan dan kaki belakang, dan perpindahan medial-lateral yang besar dari pusat tekanan kaki (center of pressure/COP). Postur yang rendah dapat dikaitkan dengan kecepatan rendah dari Tai Chi dan aktivitas otot yang terkoordinir dari ekstremitas bawah. Durasi aktivasi dari otot-otot kaki, terutama ekstensor lutut adalah secara signifikan dipengaruhi oleh kecepatan pergerakan Tai Chi. ${ }^{5}$

Mempraktikkan Tai Chi pada kecepatan yang berbeda dapat mengubah peran fungsi otot dalam kontrol gerakan. Sebagai tambahan, pola aktivasi spasial, temporal dan neuromuskular dari TCG berbeda dengan gait normal. Dibandingkan dengan gait normal, TCG mempunyai durasi siklus yang 
lebih lama, dan durasi posisi kaki tunggal; pergerakan sendi yang lebih besar pada ankle dorsi/fleksi plantar, fleksi lutut, fleksi panggul, dan abduksi panggul; pergeseran tubuh bagian lateral yang lebih besar, dan keterlibatan dorsofleksi pergelangan, ekstensi lutut, fleksor dan abduktor panggul, aksi isometrik dan eksentrik yang lama, serta koaktivasi yang lebih lama dari otot secara signifikan. ${ }^{1}$

Bentuk aktivasi otot normal dicirikan oleh aktivasi dan relaksasi yang berhubungan dengan grup otot antagonis dan agonis selama aktivitas spesifik. Koaktivasi dari grup otot merupakan suatu strategi umum yang diadopsi untuk mengurangi regangan dan gaya geser pada sendi. ${ }^{1}$

Usia dapat memengaruhi karakterisitik dari performa Tai Chi. Orang yang lebih tua mempraktikkan Tai Chi dalam postur yang lebih tinggi karena kelemahan otot atau degenerasi sendi lutut. Tai Chi gait gaya geser dan torsi bidang frontal yang meningkat dibanding gait normal, tetapi gaya geser pada sendi ekstremitas bawah selama TCG adalah lebih rendah pada subjek yang lebih tua dibanding dengan orang yang muda. ${ }^{1}$

\section{Tai Chi untuk Promosi Kesehatan}

Berdasarkan metaanalisis, latihan Tai Chi secara signifikan memperbaiki kapasitas aerobik, terutama pada usia pertengahan, perempuan, dan laki-laki yang lebih tua. Pengambilan oksigen puncak merupakan indikator terbaik untuk kapasitas aerobik dan prediktor terkuat risiko kematian di antara subjek normal dan pasien dengan penyakit kardiovaskular. ${ }^{1}$

Tai Chi dilakukan dalam posisi semisquat dan berbagai derajat kontraksi konsentrik dan eksentrik dibutuhkan untuk postur unik ini. ${ }^{1}$ Dalam percobaan acak baru-baru ini, program 16 minggu Tai Chi dengan 3 sesi per minggu juga menginduksi peningkatan signifikan dalam kekuatan ekstensor lutut eksentrik pada subjek perempuan lansia. ${ }^{3}$

Gerakan Tai Chi didominasi oleh perubahan posisi badan, rotasi badan, dan berdiri dengan satu kaki pada posisi yang berbeda. Kontrol sendi yang halus dengan koordinasi otot dibutuhkan selama gerakan, dan karenanya fungsi keseimbangan dapat bertambah baik dari mempraktikkan Tai Chi jangka panjang. Dalam studi yang menggunakan tes keseimbangan sederhana (seperti durasi waktu selama berdiri satu kaki dengan mata terbuka atau tertutup), praktisi Tai Chi yang lebih tua menunjukkan kontrol postural lebih baik dibanding subjek yang tidak melakukannya. ${ }^{1}$

Sebuah studi yang menggunakan sistem keseimbangan terprogram menunjukkan tidak adanya perbedaan pada praktisi Tai Chi jika dibandingkan dengan grup kontrol dalam kondisi sederhana (seperti ayunan postural pada posisi berdiri dengan mata terbuka atau tertutup). Sebaliknya, praktisi Tai Chi menunjukkan keseimbangan yang lebih baik dalam kondisi kompleks seperti mata tertutup dengan permukaan yang bergoyang, penglihatan bergoyang dengan permukaan bergoyang, dan tes perpindahan berat ke depan dan ke belakang. ${ }^{1}$

Program latihan optimal untuk dewasa dapat menangani komponen kebugaran fisik terkait kesehatan dari kebugaran kardiorespirasi, kekuatan otot dan daya tahan, fleksibilitas, komposisi tubuh, dan kebugaran neuromotor. Penelitian sebelumnya menyarankan bahwa Tai Chi memperbaiki kebugaran terkait kesehatan dan fungsi psikososial. Sebagai tambahan, Tai Chi termasuk pemanasan dan pendinginan, latihan peregangan, dan progresi bertahap volume dan intensitas, dan kelihatan sangat membantu untuk mengurangi cedera otot dan komplikasi. ${ }^{1}$

\section{Tai Chi terhadap Penyakit Stroke}

Pasien pascastroke biasanya akan mengalami fungsi fisik yang buruk dan penurunan kualitas hidup secara signifikan. ${ }^{4}$ Cara berjalan dan keseimbangan yang buruk akan meningkatkan risiko jatuh sebagai komplikasi tersering pasien stroke selama rehabilitasi. ${ }^{5}$ Oleh karena itu dibutuhkan intervensi yang efektif untuk meningkatkan fungsi fisik dan kualitas hidup pasien-pasien tersebut. ${ }^{6}$

Tai Chi terdiri dari gerakan lambat, anggun, dan tepat yang dilakukan dengan pusat gravitasi yang rendah. ${ }^{7}$ Gerakan ini merupakan intervensi unik yang mengintegrasikan komponen fisiologi, psikologi, fisiologik, psikologik, emosi, spiritual, dan perilaku. Inti dari latihan Tai Chi adalah menyerupai 
teknik rehabilitasi stroke Bobath dan proprioceptive neuromuscular facilitation (PNF) yang membuat Tai Chi sesuai dengan rehabilitasi stroke. ${ }^{8}$ Suatu tinjauan sebelumnya juga menyarankan bahwa Tai Chi adalah aman dan alternatif untuk mereka dengan disabilitas dan dapat memberikan suatu modalitas latihan tambahan rehabilitasi untuk pasien stroke. ${ }^{9}$

Kebanyakan gerakan Tai Chi yang bersifat spiral alamiah bertujuan untuk memperkuat anggota gerak dan otot inti dari perut dan punggung. Ini sesuai dengan teknik rehabilitasi stroke konvensional yang berfokus terhadap latihan kekuatan untuk anggota gerak dan badan, karena Tai Chi dipraktikkan saat berdiri dan sebagai suatu latihan menahan beban untuk meningkatkan keseimbangan yang menyerupai rehabilitasi konvensional. Kebutuhan bernapas dalam-dalam dan relaksasi dari tubuh dan pikiran ketika mempraktikkan Tai Chi konsisten dengan terapi rehabilitasi stroke yang mendorong pasien untuk rileks dan tetap tenang untuk mendapatkan penyembuhan yang lebih baik. Salah satu prinsip terpenting dari Tai Chi adalah "conquering the unyielding with the yielding" yang sesuai dengan terapi fisioterapi dari spastisitas dengan manipulasi lemah lembut. ${ }^{9}$

Latihan Tai Chi meningkatkan fleksibilitas dan kekuatan otot, mencegah postur abnormal dan bentuk renjatan, dengan demikian meningkatkan kemampuan untuk kontrol gerakan dan fungsi keseimbangan pada pasien dengan penyakit serebrovaskular dan Parkinson. ${ }^{6}$ Efek Tai Chi dalam rehabilitasi stroke telah dipelajari dan dalam beberapa kasus sudah digabungkan ke dalam program rehabilitasi stroke. ${ }^{10}$

Kemampuan berjalan penting pada pasien stroke untuk mencegah jatuh dan konsekuensi yang lebih berat. Aktivitas fisik mempunyai dampak positif pada kualitas hidup dan kesehatan mental. Tai Chi sebagai suatu karakteristik terapi fisik dengan sejarah panjang harusnya mempunyai efek yang serupa dan sudah dibuktikan dalam beberapa studi terbaru. ${ }^{1}$ Dalam studi terbaru, timed up and go (TUG) dan short physical performance battery (SPBB) digunakan untuk mengevaluasi efek latihan Tai Chi terhadap gaya berjalan pada pasien stroke dan ternyata secara statistik hasil yang lebih baik didapat pada pasien yang menjalani Tai Chi. ${ }^{6}$

Periode singkat latihan Tai Chi dapat meningkatkan keseimbangan berdiri. Ketika mempraktikkan Tai Chi, pasien secara berkelanjutan memindahkan berat mereka dan mengubah sandaran dasar di antara kedua kaki mereka ketika secara bersamaan melakukan pergerakan lengan. Pendekatan ini dapat menjelaskan peningkatan fungsi keseimbangan berdiri dan pergerakan ini dan perpindahan pusat gravitasi adalah spesifik untuk Tai Chi. ${ }^{11}$

Sebagai tambahan, propioseptif badan, ekstremitas bawah dan kemampuan untuk mengontrol otot serta sendi secara halus dapat ditingkatkan dengan latihan Tai Chi yang dapat memberikan konstribusi terhadap kontrol keseimbangan yang lebih baik. ${ }^{11}$ Keseimbangan ini sangat penting pada pasien stroke untuk mencegah jatuh dan konsekuensi yang lebih buruk. Efek positif terhadap jatuh tersebut dilaporkan rendah pada studi Taylor-Piliae dkk setelah latihan Tai Chi beberapa minggu. ${ }^{12}$

\section{Studi Klinis Tai Chi untuk Rehabilitasi Stroke}

Taylor-Pilliae dkk juga meneliti bagaimana Tai Chi memengaruhi fungsi fisikal termasuk angka jatuh dan kualitas hidup pada pasien stroke. Terdapat 145 subjek dengan usia 50 tahun atau lebih dan dengan post stroke 3 bulan atau lebih. Subjek secara acak dibagi ke dalam 3 grup, yaitu Tai Chi bentuk singkat, latihan kekuatan dan rentang gerakan, serta perawatan biasa. Selama studi 12 minggu, grup Tai Chi dan menjalani kelas 1 jam sebanyak tiga kali seminggu, sementara perawatan biasa menerima bahan tulisan sumber daya pada aktivitas fisik dan ditelepon setiap minggu untuk melihat perhatian individu dan mengawasi kesehatan mereka. Hasilnya menunjukkan bahwa intervensi Tai Chi mengurangi angka jatuh lebih efektif dibanding latihan kekuatan dan rentang gerakan atau perawatan biasa. ${ }^{12}$

Zheng dkk melihat efek melakukan Tai Chi secara persisten pada pasien stroke iskemik selama 1 tahun dapat meningkatkan aktivitas hidup sehari-hari dan status emosional. ${ }^{13} \mathrm{Xi}$ Lu dkk juga menginvestigasi latihan visual imagery Tai Chi 
sebagai teknik rehabilitasi suplemental untuk pasien stroke yang berbaring di tempat tidur. Sebanyak 32 subjek pada grup kontrol mendapatkan rehabilitasi konvensional dan 35 subjek menerima latihan visual imagery Tai Chi ditambah terapi konvensional. Didapatkan bahwa latihan tersebut efektif meningkatkan kekuatan mencubit, fungsi motorik dan aktivitas kehidupan sehari-hari pada pasien stroke yang mengenai ekstremitas atas. ${ }^{3}$

Tai Chi juga menunjukkan keuntungan terhadap fungsi psikologikal. Wang dkk secara acak menugasi 34 pasien stroke dengan latihan Tai Chi atau rehabilitasi konvensional dalam sesi grup sekali seminggu selama 12 minggu. Setelah latihan grup Tai Chi mengalami peningkatan untuk kualitas tidur, skor kesehatan secara umum, skor ansietas/insomnia, dan skor depresi. ${ }^{1}$

\section{KESIMPULAN}

Tai Chi merupakan latihan tradisional Tiongkok yang mengintegrasikan latihan pernapasan ke dalam pergerakan tubuh. Terdapat beberapa alasan untuk merekomendasikan Tai Chi sebagai program latihan untuk orang sehat dan pasien dengan penyakit kronik. Pertama, Tai Chi tidak membutuhkan fasilitas khusus atau peralatan mahal. Kedua, Tai Chi adalah efektif dalam meningkatkan kapasitas aerobik, kekuatan otot, dan keseimbangan serta dalam memperbaiki faktor risiko kardiovaskular. Ketiga, Tai Chi merupakan latihan murah, teknologi sedikit, dan dapat dengan mudah dilakukan dalam suatu komunitas.

Tai Chi mungkin dapat dipertimbangkan untuk rehabilitasi stroke karena mempunyai efek menguntungkan terhadap kemampuan berjalan. Akan tetapi, uji kontrol acak dengan suatu studi kohort skala besar dari pasien dan follow-up jangka panjang dibutuhkan untuk menentukan dengan tegas efek menguntungkan dari Tai Chi terhadap keseimbangan berdiri dan kemampuan berjalan.

\section{DAFTAR PUSTAKA}

1. Lan C, Chen SY, Lai JS, Wong AM. Tai chi chuan in medicine and health promotion. Evid Based Complement Alternat Med. 2013;2013:1-17.

2. Liang SY. Simplified tai chi chuan: 24 postures with applications and standard 48 postures. YMAA Publication Center, Inc. 2015. h. 41-88.

3. Lu X, Hui-Chan CW, Tsang WW. Effects of tai chi training on arterial compliance and muscle strength in female seniors: a randomized clinical trial. Eur J Prev Cardiol. 2013;20(2):238-45.

4. Go AS, Mozaffarian D, Roger VL, Benjamin EJ, Berry JD, Borden WB, dkk. Heart disease and stroke statistics-2013 update: a report from the American Heart Association. Circulation 2013;2(1)7:e6-245.

5. Tan KM, Tan MP. Stroke and falls-clash of the two titans in geriatrics. Geriatrics. 2016;1(4):1-15.

6. Yan-Li G, Wang W, Liu GL, Zhang Y. Effects of tai chi on balance and gait in stroke survivors: a systematic meta-analysis of randomized controlled trials. Journal of rehabilitation medicine. 2018;50(7):582-8.

7. Lan C, Chen SY, Lai JS, Wong AM. Tai chi chuan in medicine and health promotion. Evid Based Complement Alternat Med. 2013;2013:502131.

8. Zhang Y, Liu H, Zhou L, dkk. Applying tai chi as a rehabilitation program for stroke patients in the recovery phase: study protocol for a randomized controlled trial. Trials. 2014; 15:484.

9. Zhang Y, Ning Y, Liu H, Zhou L, Zou Y, Li Z. Current trends in tai chi for stroke rehabilitation. Journal of Traditional Chinese Medical Sciences. 2015;2(3):135-9.

10. Zhang Y, Liu H, Zhou L, Chen K, Jin H, Zou Y, dkk. Applying tai chi as a rehabilitation program for stroke patients in the recovery phase: study protocol for a randomized controlled trial. Trials. 2014;15:484.

11. Kim H, Kim YL, Lee SM. Effects of therapeutic tai chi on balance, gait, and quality of life in chronic stroke patients. Int J Rehabil Res. 2015;38(2):156-61.

12. Taylor-Piliae RE, Hoke TM, Hepworth JT, Latt LD, Najafi B, Coull BM. Effect of tai chi on physical function, fall rates and quality of life among older stroke survivors. Arch Phys Med Rehabil. 2014;95(5):816-24.

13. Zheng WC, Zhang YH, Jiang RY, Chen XQ, Xiao WM. Effects of persistent tai chi on rehabilitation in ischemic stroke: a prospective randomized controlled trial. Chin J Integr Med Cardio- Cerebrovasc Dis. 2015;13:304-7. 